\title{
ANÁLISE CRÍTICA DAS CLÁUSULAS DISPUTE BOARD: EFICIÊNCIA E CASOS PRÁTICOS
}

CRITICAL ANALYSIS OF THE DISPUTE BOARD CLAUSES: EFFICIENCY AND CASES

ANÁLISIS CRÍTICO DE LAS CLÁUSULAS DISPUTE BOARD: EFICIENCIA Y CASOS PRÁCTICOS

Marcia Carla Pereira Ribeiro ${ }^{1}$

Caroline Sampaio de Almeida ${ }^{2}$

RESUMO

Em pesquisa recente, capitaneada pela Escola de Direito do Rio de Janeiro da Fundação Getúlio Vargas, foram divulgados números alarmantes de processos existentes, especialmente no Supremo Tribunal Federal, os quais reforçam a cultura de litígio pátria e corroboram com o reconhecimento da sobrecarga da estrutura deficitária do Judiciário. Essa realidade processual brasileira, todavia, não se coaduna com princípios de eficiência empresarial que reclamam mecanismos ágeis e respostas imediatas às situações de impasse que, mais cedo ou mais tarde, se instalam num ambiente negocial. Na atual conjuntura econômica do Brasil, que tem uma expectativa de investimentos públicos na área de infraestrutura no montante aproximado de $\mathrm{R} \$ 2$ trilhões até o ano de 2016, os profissionais da área de Direito devem estar atentos e preparados para a possibilidade de utilização dos Dispute Boards, cujo mecanismo prestigia a multidisciplinaridade e a cooperação entre os agentes econômicos, mas apresenta também alguns riscos, os quais merecem especial atenção. Partindo desse contexto, o presente artigo volta-se ao estudo da prática dos Dispute Boards nos contratos de infraestrutura, para uma compreensão mais ampla de sua operacionalização.

PALAVRAS-CHAVE: Dispute boards. Análise econômica do direito. Relações empresariais. Contratos de infraestrutura. Cooperação.

\begin{abstract}
In recent research study led by the Escola de Direito do Rio de Janeiro [Rio de Janeiro School of Law] of the Getúlio Vargas Foundation, alarming numbers of existing lawsuits had been divulged, especially in the Supreme Federal Court, that reinforce the native culture of litigation, and corroborate in the recognition of the legal system as a deficient and overworked structure. This Brazilian procedural reality, however, is not in accordance with principles of enterprise efficiency that demand effective mechanisms and immediate answers to the situations of stalemate that, sooner later, emerge in the business environment. In the current economic scenario of Brazil, which has a forecast of approximately $R \$ 2$ trillion in public investments by 2016 , notably in the area of infrastructure, legal professionals must be alert and prepared for the possibility of the use of Dispute Boards, whose mechanism favors multidiscipline actions and cooperation between the economic agents, but also presents some risks that deserve special attention. Based on this context, this article focuses on the practical study of the Dispute Boards in infrastructure contracts, seeking to gain a deeper insight into the way they operate.
\end{abstract}

1 Doutora em Direito pela UFPR. Pós-doutorado pela EDESP/FGV. Professora Titular de Direito Societário na PUCPR e Professora Adjunta de Direito Comercial da UFPR. Procuradora e advogada no Estado do Paraná. Curitiba, Paraná, Brasil. E-mail: mcarlaribeiro@uol.com.br

2 Mestre em Direito Econômico e Ambiental pela PUCPR. Doutoranda em Direito pela USP. Advogada no Estado do Paraná. Curitiba, Paraná, Brasil. E-mail: carolinealmeida@hotmail.com 
KEYWORDS: Dispute boards. Economic analysis of the Law. Managerial relations. Infrastructure contract. Cooperation.

\section{RESUMEN}

En investigación reciente, conducida por la Escuela de Derecho de Rio de Janeiro de la Fundación Getúlio Vargas, se divulgaron números alarmantes de procesos existentes, especialmente en el Supremo Tribunal Federal, que refuerzan la cultura patria de litigio y corroboran el reconocimiento de la sobrecarga de la estructura deficitaria del Poder Judicial. Sin embargo, esa realidad procesal brasileña no se coaduna con principios de eficiencia empresarial que demandan mecanismos ágiles y respuestas inmediatas a las situaciones de estancamiento que, más tarde o más temprano, se instalan en un ambiente de negocios. En la actual coyuntura económica de Brasil, que tiene una expectativa de inversiones públicas en el área de infraestructura en un monto aproximado de dos billones de reales hasta el año 2016, los profesionales del área de Derecho deben estar atentos y preparados para la posibilidad de utilización de los Dispute Boards, cuyo mecanismo prestigia la multidisciplinaridad y la cooperación entre los agentes económicos, aunque presenta también algunos riesgos que merecen especial atención. Partiendo de ese contexto, el presente artículo se vuelca al estudio de la práctica de los Dispute Boards en los contratos de infraestructura para una comprensión más amplia de su operacionalización.

PALABRAS CLAVE: Dispute boards. Análisis económico del Derecho. Relaciones empresariales. Contratos de infraestructura. Cooperación

\section{NOTAS INTRODUTÓRIAS}

Recentemente, foi apresentada no Brasil uma pesquisa denominada "Supremo em Números", ${ }^{3}$ realizada pela Escola de Direito do Rio de Janeiro da Fundação Getulio Vargas (FGV), sob a coordenação de Pablo Cerdeira, Diego Werneck e Joaquim Falcão. A pesquisa apresenta as principais demandas que chegam ao Supremo Tribunal Federal, apontando para a facilidade de acesso, por meio das 37 classes processuais, no período compreendido entre 2007 e 2009, assim como seus maiores litigantes, dos quais o setor público aparece em $90 \%$ de todos os processos. Ao lado disso, dos processos analisados pelo Supremo Tribunal Federal, paradoxalmente, 8\% (o equivalente a 96.292 mil) são oriundos dos Juizados Especiais, procedimento criado para agilizar a solução das controvérsias, mas que acaba por desembocar no mesmo sistema e seus efeitos protelatórios, característicos do Poder Judiciário pátrio.

Esses números reforçam a cultura de litígio pátria e corroboram com o reconhecimento da sobrecarga da estrutura deficitária do Judiciário e também confirmam a tendência de morosidade processual, especialmente em relação aos processos que são analisados por terceiras ou quartas instâncias, qual seja, pelos tribunais superiores.

A realidade processual brasileira não se coaduna com princípios de eficiência empresarial que reclamam mecanismos ágeis e respostas imediatas às situações de impasse que, mais cedo ou mais tarde, se instalam num ambiente societário ou negocial.

Como alternativas ao recurso ao Poder Judiciário, e até mesmo às outras formas de solução de controvérsias, emergem as Dispute Boards (DB), técnicas de administração dos contratos e dos conflitos deles decorrentes, segundo as quais a crise nas relações contratuais será mais eficientemente resolvida mediante "construção" da solução pelas partes do que por decisões adjudicadas e impostas por uma determinada autoridade, sem que se possa ter controle preciso do tempo e do custo do processo.

Parte-se de uma perspectiva focada na construção de determinada relação para o futuro, ao contrário do Judiciário, cuja atuação se concentra basicamente na tentativa de restabelecer o status 3 Disponível no site http://www.supremoemnumeros.com.br/ em 31.05.2011. 
quo ante das relações sociais submetidas ao seu crivo (olhar para o passado), o que potencializa a animosidade entre as partes, já que, numa solução imposta, a tendência será de consagração de apenas uma das partes como vencedora.

No Brasil, em particular, a euforia por realizar investimentos em obras públicas, visando atender às demandas da Copa de 2014 e Olimpíadas de 2016, tem despertado a atenção de diversos profissionais para a utilização dos Dispute Boards, mecanismo ainda incipiente e pouco conhecido no país. É justamente nesses contratos de infraestrutura que os Dispute Boards encontram campo fértil para o seu crescimento e desenvolvimento, pois a incompletude que lhes é inerente permite, com sua abertura, a criação de instrumentos específicos de soluções, estimulando o diálogo entre as partes envolvidas e a perenidade das relações empresariais.

Todavia, para que o uso de cláusula DB seja eficaz, é imprescindível um arcabouço jurídico que confira enforcement às disposições contratuais, valorizando a autonomia privada.

Da mesma forma do que acontece pela via do consenso, quando se busca a solução frente ao Poder Judiciário, é imprescindível que as decisões sinalizem para o mercado a força vinculativa do pactuado, de maneira a garantir previsibilidade e calculabilidade que fomentem o incentivo econômico aos agentes que atuam no mercado.

Por outro lado, a resolução das disputas jurídicas de caráter negocial tem valor monetário, representado pelo risco em jogo; a decisão de tais controvérsias implica quase que necessariamente a alocação do risco entre as partes. A decisão sobre quanto do risco incide sobre cada parte pode criar um incentivo para o comportamento futuro, não apenas das partes envolvidas, mas também das outras que estiverem numa situação semelhante.

O Poder Judiciário tem um papel essencial não apenas ao fazer cumprir as promessas firmadas entre as partes - respeitando, p.ex., uma cláusula DB ou atribuindo maior peso às recomendações dos DB mesmo que não vinculativas às partes -, como na promoção da troca e do incentivo à cooperação. Tal conduta tem o condão não apenas de reduzir a incerteza e o risco, como também de atrair maiores investimentos por parte dos agentes econômicos cujo comportamento impacta diretamente no desenvolvimento econômico de uma sociedade.

É o retrato da conformação da ordem econômica, por meio dos princípios constitucionais da segurança jurídica, duração razoável do processo, livre iniciativa e autonomia privada (arts. $5^{\circ}$, incs.XXXVI e LXXVIII, e art. 170, caput, e inc.VI, todos da CF), num viés de inter-relação entre economia dos conflitos, lei e atividade econômica em si, em que o Direito cumpre sua função de operacionalização das relações de mercado, porquanto comprometido com os referidos princípios que instrumentalizam o seu funcionamento.

$\mathrm{Na}$ atual conjuntura econômica do Brasil, que tem uma expectativa de investimentos públicos na área de infraestrutura no montante aproximado de $R \$ 2$ trilhões até o ano de 2016, os profissionais da área de Direito devem estar atentos e preparados para a possibilidade de utilização dos Dispute Boards que prestigiam a multidisciplinaridade e a cooperação entre os agentes econômicos, mas também devem ser alertados para alguns riscos que o referido mecanismo proporciona.

Partindo dessas considerações, o presente artigo volta-se ao estudo da prática dos Dispute Boards nos contratos de infraestrutura, para uma compreensão mais ampla de sua operacionalização.

\section{PREMISSAS}

Antes que o trabalho desenvolva a temática do DB propriamente dita, entende-se oportuna a fixação de algumas premissas que terão implicações diretas em relação aos demais tópicos.

Adianta-se aqui que a aceitação de cláusula de Dispute Board relaciona-se a dois momentos. Um ex ante, momento em que se admite a adoção da cláusula ao mesmo tempo em que se reconhece a possibilidade de surgimento de litígios no decorrer do contrato e se valora a busca da solução particular, em detrimento do recurso ao poder externo, no caso, ao Poder Judiciário. Neste momento, talvez mais do que no posterior (ex post), relacionado às condições para que os bons resultados sejam atingidos, destaca-se a importância do comportamento colaborativo. 
As premissas, por escolha metodológica, terão suas bases extraídas de dois estudos, um para cada subitem, que não foram realizados pensando-se no DB, mas cujos resultados podem ser proveitosamente projetados na busca da eficácia da contratação da cláusula.

\section{CONDIÇÕES PARA COOPERAÇÃO}

A natureza do negócio e a possibilidade de preservação dos vínculos negociais no tempo exercem um papel essencial na configuração do ambiente cooperativo.

Vale dizer, a perspectiva da existência de um futuro pode alterar de forma significativa a conduta do agente econômico. Logo, ambientes em que se negocia com a perspectiva de médio ou longo prazo ou, ainda, tendo-se em mente a possibilidade de renovação de vínculos, tendem à cooperação e podem ser tomados como forma de expressão do grau de desenvolvimento de determinada sociedade. Sociedades que se valem primordialmente de relações instantâneas, pautadas na busca da maior lucratividade individual de forma não consentânea com os benefícios almejados pela outra parte dificilmente atingirão os mais elevados graus de desenvolvimento, pela carência de estabilidade e previsibilidade nos negócios.

Por tais motivos, torna-se relevante, quando se pensa em mecanismos de solução de controvérsias que se apresentem como alternativas ao recurso direto ao Poder Judiciário, considerar quais os fatores que podem maximizar comportamentos de cooperação.

Para que o ambiente de cooperação aconteça, é importante que os agentes visualizem a perspectiva de retomada de negócios com a mesma contraparte, que possam reconhecer-se quando do reencontro e que tenham acesso a informações sobre o comportamento recíproco até o momento. ${ }^{4}$

Romper com o previamente pactuado poder ser estimulado por fatores como o temor ou não temor de retaliações futuras. Se há a expectativa de novos negócios, a tendência será de não romper com o pactuado, sob o risco da perda de boas oportunidades futuras. Por outro lado, as incertezas quanto ao futuro, a partir de fatores primários como a própria existência futura da pessoa da contraparte, ou negociais, como interesse ou não na realização de renovação, funcionam como elementos de oposição à cooperação. Somando-se à aspiração de lucratividade imediata e extremada, são fatores que exercerão papel fundamental na extensão da janela para o futuro ${ }^{5}$, por consequência, no comportamento dos agentes.

Tornar as relações mais duradouras ou mais frequentes são bons indutores de comportamento de cooperação, assim como limitar o número de potenciais participantes pela ferramenta, por exemplo, da especialização que irá naturalmente delimitar a possibilidade de concorrentes. Hierarquia e organização também favorecem a cooperação porque promovem ajustamento de condutas e sua otimização.

Decompor os objetivos também é uma estratégia interessante, pois pode tornar o rompimento de uma etapa bem menos atrativo do que o resultado do ganho geral. ${ }^{6}$

No campo dos contratos complexos e de duração considerável, torna-se bastante previsível que nem todo tipo de situação que possa vir a ocorrer durante a vigência e a produção de seus efeitos esteja prefixada no contrato. Às vezes e até mesmo de forma natural, as partes não têm a confirmação de suas expectativas iniciais, até mesmo por um erro de compreensão ou interpretativo do contrato. Logo, nisto o DB pode exercer um papel essencial e eficiente e que mais uma vez pode ser associado ao comportamento de colaboração.

Quando faltam incentivos à cooperação, algumas vezes o Estado toma para si o papel de exigir uma determinada conduta, impondo penas quando de seu não cumprimento e, desta forma, age de maneira a modificar um resultado. Como no caso da fixação de estruturas alternativas para solução de conflitos não há como, em nosso sistema jurídico, impor-se uma atitude de abstenção de exercício do direito de ação, a não ser pela adesão das partes à atitude vinculativa ao instrumental adequado

4 AXELROD, Robert. The evolution of cooperation. New York: Basic Books, Inc., Publishers, 1984.p. 125.

5 AXELROD, Robert. Ob. cit.. p. 127.

6 AXELROD, Robert. Ob. cit.. p. 132. 
à adoção de medidas como DB. Porém a firmeza do Poder Judiciário, adotando uma posição de isenção de interferência nas esferas de litígio coordenados contratualmente a partir de estruturas não estatais de resolução de conflitos, é essencial para que institutos como DB ingressem de forma definitiva na agenda das relações de caráter negocial.

Há outros elementos, ainda, associados à cooperação. Uma dose de altruísmo, que no campo negocial pode muito bem estar relacionado a valores diferentes do desprendimento da caridade, como uma opção pelo bem-estar alheio como forma de preservação de uma relação de caráter comercial, vale dizer, agir de forma não desinteressada, assegurando um benefício à contraparte, pode gerar um ambiente de retribuição, compatível com a resolução de conflitos no âmbito privado. Ensinar a reciprocidade também exerce seu papel, induzindo-se à atitude de cooperação se o que se pretende é que o outro também a exerça de forma simétrica. Por fim, reconhecer e premiar condutas anteriores são também instrumentos úteis na cultura da cooperação. ${ }^{7}$

Assim, ao optarem pela adoção de cláusula DB, as partes assumem uma atitude de colaboração que será tão mais facilitada quanto mais sejam reconhecíveis alguns dos fatores indicados neste item. Mas não se deve descartar aqui o fato de que por detrás de todas as opções negociais estará a busca de alternativas que reduzam os custos de transação, aumentando a perspectiva de lucratividade do empreendimento.

Ainda assim, previamente adota-se a perspectiva do DB e expõe-se como atitude de cooperação que decorrerá de um sistema que se mostre suficiente à provocação de estímulos à sua adoção, mediante o assegurar de recompensas aos aderentes que desestimulem o inadimplemento ou o recurso ao Poder oficial.

O próximo item discorrerá brevemente sobre os fatores que, a partir de uma experiência controlada, mostraram-se aptos a interferir nos melhores resultados obtidos por meio de soluções mediadas.

\section{CONDIÇÕES PARA AS MELHORES SOLUÇÕES NEGOCIADAS}

Uma experiência recentemente relatada em artigo publicado na American Law and Economics Review ${ }^{8}$ buscou, ainda que se valendo de um experimento controlado, realizado com estudantes de direito que foram divididos em duplas, receberam informações e atuaram, um na representação do demandante e outro do demandado, dados acerca dos fatores que podem interferir na conclusão de melhores acordos.

O dado fictício utilizado no exercício embasou-se no suposto fato do demandante ser um profissional de mais de 50 anos que foi despedido de seu emprego, mesmo tendo tido boas avaliações de desempenho. O demandante alega ter sido despedido em razão exclusivamente de sua idade, o que Ihe possibilitaria ingressar com uma ação de indenização pelo período em que se manteve fora do mercado de trabalho, ou seja, até a nova contratação por outro empregador. 0 demandado invoca em sua defesa que o desempenho do demandante, muito embora tenha sido avaliado positivamente, encontrava-se em declínio comparativamente há anos anteriores e que outros empregados na mesma faixa de idade foram mantidos na empresa.

A pesquisa elegeu sete fatores que, em tese, estariam relacionados à obtenção dos melhores resultados para ambas as partes, numa situação de negociação para evitar a demanda judicial.

Em que pesem as limitações decorrentes da estrutura da experiência, aplicada no universo composto por estudantes de direito e conduzida sem que pudesse representar todas as facetas do mundo real, algumas conclusões merecem ser destacadas para fins de identificação do perfil profissional de um negociador e que pode ser útil em termos de DB.

A pesquisa identificou, em ordem de importância, a interferência dos seguintes fatores para a obtenção dos melhores resultados na composição dos interesses: ${ }^{9}$

7 AXELROD, Robert. Ob. cit.. p. 134-141.

8 KOROBKIN, Russell; DOHERTY, Joseph. Who Wins in Settlement Negotiations. American Law and

Economics Review, Vol. 11, n. 1, 2009, pp. 162-208.

9 KOROBKIN, Russell; DOHERTY, Joseph. Ob. Cit.. p. 198. 
1) A estimativa dos negociadores no que se refere ao limite de preço da contraparte - quanto mais alta a estimativa subjetiva dos negociadores com relação ao limite de negociação da outra parte, maior o benefício obtido a partir da negociação;

2) Negociadores do sexo masculino obtêm maiores benefícios do que os do sexo feminino cabendo observar que, por outro lado, as mulheres tendem a ter maiores preocupações com a durabilidade das relações econômicas e costumam adotar de forma mais intensa do que os homens critérios relacionados à justiça no resultado final;

3) O montante da primeira oferta entabulada na negociação - qual seja, apresentar a primeira oferta e fazê-lo de forma corajosa, conduz a acordos que adotam resultados mais expressivos em relação à parte que apresenta a primeira oferta;

4) As metas dos negociadores - a pesquisa indicou que quanto mais agressiva a meta, maior a probabilidade de sucesso;

5) O entusiasmo dos negociadores em relação a tornar o caso litigioso - quanto maior a perspectiva de solução judicial favorável, maior a possibilidade de realização de acordos favoráveis.

6) A confiança dos negociadores em relação à sua habilidade para conduzir as negociações; e

7) A opinião dos negociadores com relação ao que se pode considerar justo.

Como toda a pesquisa empírica dirigida, os resultados expressos no artigo não podem ser tomados como absolutamente replicáveis em todos os contextos, o que não retira o interesse em que sejam realizados outros experimentos e pesquisas que possam trazer critérios que auxiliem na escolha dos personagens que serão utilizados como negociadores, na busca de soluções mais eficientes para situações de crise normais em contratos de duração expressiva e prestações diferidas.

Feitas as considerações sobre fatores objetivos e subjetivos que se relacionam ao ambiente de negociação colaborativa, o artigo passa a discorrer de forma específica sobre a DB.

\section{CARACTERÍSTICAS}

A fim de se permitir uma maior compreensão das $D B$, optou-se por desde logo contextualizarse a sua aplicação em contratos que, seja em razão de suas peculiaridades e duração, aparentam maior probabilidade de estabelecimento de situações conflituosas que possam ser resolvidas sem recurso ao estabelecimento de uma lide. Para tal fim, elegeu-se a modalidade dos contratos de construção.

Os contratos de construção são, conforme já mencionado, típicos contratos incompletos em razão da impossibilidade de descreverem todas as contingências, as quais podem ou não ocorrer durante o curso da construção. Para administrá-las, porém, a maioria das formas padronizadas de contratos de construção fornece regras para partilha de riscos, variações e resolução de controvérsias.

A incompletude do contrato é fruto do próprio ambiente econômico que, por características inerentes, é eivado de imperfeições e incertezas. Ainda que as negociações se estendessem por maior termo (e custo), dificilmente se teria por resultado estipulações que erradicassem ou cobrissem de forma eficiente os riscos existentes. Isto sem se falar na existência ou não de mecanismos de controle quanto ao cumprimento do pactuado em contratos mais minuciosos. ${ }^{10}$ Portanto operar com contratos incompletos é uma opção e uma necessidade, mas, quanto mais complexas (e duradouras) as relações jurídicas, maior a probabilidade de instalar-se uma situação de divergência.

A simples divergência de opiniões entre as partes contratantes na interpretação de documentos contratuais geralmente implicará sérias discussões. Se as partes falharem em resolver tais divergências por meio de negociação, poderão recorrer à arbitragem ou ao processo judicial.

Economicamente, pode se mostrar mais eficiente para os envolvidos evitar chegar-se à instalação de uma lide, quer venha a ser apresentada perante árbitros ou Poder Judiciário. Qualquer que seja a opção, haverá custos que serão somados aos demais custos de negociação, compondo os já mencionados custos de transação. Tais custos podem ser avaliados monetariamente, quer seja

10 ARAÚJO, Fernando. Teoria Econômica do Contrato. Lisboa: Almedina, 2007. p. 151. 
no pagamento de taxas, custas e/ou honorários, ou com base no tempo que será despendido até que se obtenha a solução definitiva. Por outro lado, a possibilidade de instalação do litígio pode comprometer a relação negocial e, até mesmo, sob determinadas circunstâncias, o sucesso do empreendimento.

Não há dúvidas de que, sob o ponto de vista econômico e de eficiência, o melhor caminho para resolver divergências é prevenir que estas se transformem em conflitos formais, ou seja, o contrato bem elaborado é aquele que antecipa as disputas que podem dele decorrer e fornece as respectivas soluções ou formas para manejá-las de modo a prover uma autoprevenção de controvérsias. ${ }^{11}$

Por mais que, em tese, fosse possível pensar-se num contrato perfeito ou completo, os custos para elaboração do contrato seriam de tal monta que poderiam tornar não atrativa a realização do próprio negócio, razão de ser da elaboração do contrato. Analisando-se as duas partes que compõem um contrato, às vezes uma delas detém conhecimentos que são mais especializados sobre o objeto do contrato do que a outra, mas tais conhecimentos não chegam a ser repassados, ou o são de forma incompleta, colaborando para a formatação de um juízo equivocado ou incompleto do contratante.

Se os mercados fossem perfeitos, todos os agentes econômicos estariam inseridos num sistema em que a informação seria completa e, diante de todos os dados e do pleno exercício de suas racionalidades, tomariam suas decisões econômicas e elaborariam seus contratos. No entanto, assim como o mercado é imperfeito, os agentes tomam, no mais das vezes, decisões alicerçadas nas contingências da assimetria informacional. ${ }^{12}$

Em outras situações, nenhuma das partes tem acesso a informações completas, as quais, para serem obtidas, demandariam ou um tempo do qual não se dispõe, ou pesquisas tão acuradas e completas que, como dito, inviabilizariam a realização do negócio. São exemplos de situações que fomentam a instalação de divergências que podem se transformar em conflitos.

E, dentro dessa perspectiva, o primeiro e primordial dever de um Dispute Board é justamente evitar que uma divergência se torne conflito.

Proferir decisões ou fazer recomendações constitui papel secundário de um Dispute Board, o qual é composto geralmente por três membros - a depender da complexidade e do tamanho do projeto -, dotados de acurada experiência e conhecimento sobre determinado tipo de construção, imparciais e independentes. ${ }^{13}$

O Dispute Board é nomeado ou como consequência de uma previsão contratual ou por meio de acordo entre as partes num estágio já avançado do projeto. Será mais eficaz, todavia, se a nomeação ocorrer desde o princípio de um determinado projeto, a fim de permitir aos seus membros tornarem-se mais íntimos dos documentos contratuais, tais como condições do contrato, especificações e programas. ${ }^{14}$

Os poderes do Dispute Board e o papel a ser desempenhado por este num determinado projeto são delimitados pelas partes por ocasião de sua nomeação, a exemplo da abrangência da atuação, contemplando ou não os subcontratados. Dessa delimitação é possível extrair duas espécies de Dispute Board: resolução e adjudicação.

Na primeira, os Disputes Boards fazem recomendações (non-binding opinions) que podem ser implementadas por opção das partes ou tornar-se finais e vinculativas se nenhuma das partes levantar

11 TALPIS, Jeffrey A. Prevenção de disputas decorrentes de contratos internacionais. Tradução de Giovani Ribeiro Rodrigues Alves e Caroline Sampaio de Almeida. Revisão de Marcia Carla Pereira Ribeiro. In: MEIRELLES, Jussara Maria Leal de; RIBEIRO, Marcia Carla Pereira (Coord.). Direito e Desenvolvimento: Biomedicina, Tecnologia e Sociedade Globalizada, Belo Horizonte: Editora Fórum, 2011.

12 RIBEIRO, Marcia C. P.; GALESKI JR, Irineu. Teoria Geral dos Contratos: contratos empresariais e análise econômica. Rio de Janeiro: Elsevier, 2009.p. 94.

13 A Fédération Internationale des Ingénieurs-Conseils (FIDIC), tal como a International Chamber of Commerce (ICC), prevê formas contratuais que fornecem procedimentos consensuais ou obrigatórios para o uso e operação de Dispute Board. Na cláusula 4 do Apêndice "Condições Gerais do Acordo de Adjudicação de Disputa", edição de 1999, a FIDIC apresenta uma lista de exigências que asseguram a independência de um membro do Dispute Board.

14 OWEN, Gwyn; TOTTERDILL, Brian. Dispute Boards: procedures and practice. Thomas Telford Publishing: London, 2008, p.06. 
objeções. ${ }^{15}$ A segunda espécie, por sua vez, profere uma decisão que deverá ser implementada, embora a disputa possa ser ainda encaminhada para um tribunal arbitral ou judicial. ${ }^{16}$ Também se tornará final e vinculativa a decisão do Dispute Adjudication Board (DAB) que não sofrer objeções pelas partes. Há, ainda, uma terceira espécie que não se pode deixar de mencionar, a Combined Dispute Board (CDB), que compreende as duas primeiras espécies, pois se inicia como Dispute Review Board (DRB), mas pode mudar para um DAB durante o procedimento da controvérsia. ${ }^{17}$

A opção por uma ou outra espécie, com os respectivos detalhes - se full-term ou ad hoc ${ }^{18}$-, geralmente cabe ao contratante, que elabora os documentos contratuais com auxílio de especialistas e à luz das exigências da lei aplicável e da instituição financiadora, sujeitando-se a empreiteira a tais disposições, no caso dos contratos de construção.

Independentemente da espécie adotada, porém, as visitas dos Dispute Boards ao local do empreendimento são regulares para ter contato com as pessoas responsáveis por sua execução e observar o progresso e os problemas do projeto. Além disso, com certa habitualidade, as partes ou o próprio profissional responsável pela obra encaminha aos membros do Dispute Board relatórios do progresso do projeto notícias de divergências e outros acontecimentos relevantes, mantendo-os informados, cujas atividades passam a integrar a rotina de todos os envolvidos no projeto. Logo o Dispute Board nada mais é que parte da equipe do empreendimento que assiste às partes no sentido de impedir divergências e resolver controvérsias por meio de negociações amigáveis.

Se as partes falharem na solução de suas divergências, estas serão, por determinação, submetidas ao Dispute Board, cujos membros, desde que familiarizados com os documentos contratuais, local do empreendimento e progresso do projeto, não terão dificuldades em solucioná-las rapidamente. Ainda que a determinação seja rejeitada por uma ou ambas as partes, tal mecanismo será base para uma futura negociação amigável.

Logo, o maior benefício do Dispute Board sem dúvidas é a prevenção de disputas com a sua adiantada composição, sem que se instalem atitudes adversariais.

Após estas breves considerações sobre as vantagens em se adotar contratualmente cláusula de DB, torna-se importante também questionar as desvantagens que podem ser associadas à sua adoção.

\section{DESVANTAGENS}

Como todo mecanismo alternativo de prevenção e solução de disputas, junto com os benefícios - que na sua maioria são comuns, como celeridade, confidencialidade, cooperação, redução de custos, entre outras -, há os aspectos negativos do Dispute Board. ${ }^{19}$

As partes podem não lograr êxito em resolver suas controvérsias por meio do Dispute Board, a despeito dos custos adicionais para a sua instalação. $E$, ainda, os referidos conflitos podem ser resolvidos sem que haja tais custos.

15 Segundo o Manual de Práticas e Procedimento do Dispute Resolution Board foundation (DRBF), o Dispute Review Board corresponde a "um painel de profissionais imparciais formado no início do projeto para acompanhar o progresso da construção, estimular a evitar controvérsias e auxiliar na solução destas enquanto durar o projeto" (Capítulo 1, Seção 1, Apêndice A. Disponível em: http://www.drb. org/manual/ 1A_Case_Studies.pdf).

16 Quando as condições de contrato FIDIC incorporaram o Dispute Board como procedimento padrão de resolução de disputas, já especificaram a Dispute Adjudication Board, a qual confere mais certeza, porque a decisão tem que ser implementada, embora a parte possa ainda manter a disputa aberta para uma negociação adicional ou submetê-la à arbitragem ou ao Judiciário.

17 OWEN, Gwyn; TOTTERDILL, Brian. Ob. cit., p.10.

18 O Dispute Board full-term é designado no início do contrato para considerar todas as disputas que surgem, junto com outras dúvidas ao passo que o ad hoc é designado para uma disputa em particular após a sua instalação. Embora o full-term DB seja mais caro - as partes pagam uma taxa mensal para os Dispute Boards estudarem documentos que Ihes são enviados todo o mês, além de uma taxa adicional para os mesmos realizarem visitas regulares no local do empreendimento - tem a vantagem de seus membros já estarem familiarizados com o projeto e com as partes de tal modo que se antecipam na previsão de uma iminente disputa.

19 OWEN, Gwyn; TOTTERDILL, Brian. Ob. cit., p.7-9. 
Principalmente no que se refere ao êxito da adoção do mecanismo do $D B$, uma sondagem quanto aos fatores que interferem positivamente no estabelecimento do ambiente cooperativo pode ser eficiente.

Portanto o que foi relacionado neste artigo sobre cooperação, condições objetivas para atitudes de cooperação, como perspectiva para futuros negócios, especialidade como forma de estímulo ao estabelecimento de vínculos negociais estáveis ou repetitivos e até mesmo a valorização de experiências anteriores e adoção de uma cultura colaborativa, compõem o quadro que servirá de suporte para a garantia da efetividade do DB no ambiente contratual estabelecido.

Presentes algumas ou todas as condições de cooperação, fica acrescida a possibilidade de o DB cumprir a sua função de evitar a instalação do conflito no que possa ser resolvido na etapa da mera divergência.

Por outro lado, as decisões oriundas do Dispute Board têm natureza somente contratual e não podem ser executadas perante o Judiciário, ao passo que as decisões arbitrais, além de serem finais, são dotadas de enforcement e, portanto, exequíveis perante os tribunais judiciais.

Saliente-se, também, que o Dispute Board carece de poderes para exigir o comparecimento de testemunhas a uma audiência, sendo a oitiva informal, sem um interrogatório (crossexamination).

A finalidade do Dispute Board também pode ser desvirtuada se utilizada como teste para avaliar o outro lado do caso sob análise antes de submeter a disputa à arbitragem. E nesse aspecto, o mecanismo é considerado como mais uma etapa, muitas vezes ineficiente e desnecessária, a ser percorrida pelas partes antes de se chegar a uma efetiva resolução da controvérsia por meio da arbitragem ou do processo judicial.

Ao lado dessas desvantagens, soma-se um dos problemas mais comuns de outros mecanismos alternativos, qual seja, a imparcialidade. A título exemplificativo, em 2010, o Comitê Manual do Dispute Resolution Board Foundation (DRBF) realizou uma pesquisa, cujos participantes, baseados nas suas experiências com todas as formas de Dispute Board, responderam diversos questionamentos relativos ao uso, à formação, à especificação e à operação deste mecanismo. No tocante à imparcialidade, somente $15 \%$ dos entrevistados disseram nunca ter presenciado qualquer parcialidade, ao passo que $40 \%$ responderam ter percebido certa parcialidade dos membros do Dispute Board. ${ }^{20}$

Acrescente-se a esta última reflexão sobre as potenciais desvantagens de sua utilização, o rigor e o critério na escolha dos integrantes do DB. Como no mundo real, dificilmente uma das partes do contrato aceitará que a outra parte indique todos os integrantes de um DB, o mais prudente será partir-se do pressuposto de que cada um dos polos do contrato indicará um integrante (técnico e supostamente isento) e ambos indicarão o terceiro - nos moldes do que habitualmente ocorre quando da instalação de um procedimento de arbitragem. Neste momento, apurar-se não só a habilidade técnica dos integrantes do DB como também aspectos subjetivos, relacionados neste artigo, e que derivam de fatores como habilidade de negociação, capacidade de percepção das características do outro polo, comportamento na formulação de proposta a ser negociada perante o DB, torna-se relevante.

Após terem sido apresentados alguns aspectos vantajosos e também alguns alertas quanto ao sistema estudado, o artigo se vale de experiências práticas como forma auxiliar na compreensão do instituto.

\section{CASOS PRÁTICOS}

O conceito de Dispute Board surgiu durante o uso de um Comitê Consultivo conjunto formado por quatro pessoas no projeto Boundary Dam na década de 60 (sessenta) no Estado de Washington, cujos técnicos foram acionados para tomar decisões atinentes aos conflitos e às matérias correlatas.

20 EDGERTON, William. DRBF survey results: at look the evolution the Dispute Board process. In: Dispute Board Resolution Foundation, Forum, vol.15, maio 2011, p.14-15. Disponível em: <http:// www. sergepisapia.ca> em 10.09.2011. 
A ideia funcionou bem e o embrião do Dispute Review Board começou a crescer. ${ }^{21}$

Em 1972 o Comitê Nacional sobre Tecnologia de Escavação de Túnel promoveu um estudo visando melhorar práticas contratuais. Isso conduziu a uma publicação, em 1974, intitulada como "Melhores Práticas Contratuais para Construções Subterrâneas", na qual as consequências indesejáveis das controvérsias foram destacadas. Como resultado do estudo e da respectiva publicação, em 1975 foi estabelecido um Dispute Review Board (DRB) para o túnel Eisenhower em Colorado. Os benefícios do uso do referido mecanismo foram reconhecidos e apreciados pelas partes contratantes e o Eisenhower tornou-se um exemplo que foi seguido com entusiasmo ao longo dos USA. ${ }^{22}$

\section{EL CAJÓN HYDROELETRIC PROJECT (HONDURAS)}

Comumente apontado como um dos projetos pioneiros na adoção de Dispute Board, o El Cajon Hydroelectric Project, Honduras, de 1982 a 1986, valeu-se do referido mecanismo, na sua modalidade de Dispute Review Board (DRB), não obstante a ausência de sua previsão contratual.

O projeto foi financiado em parte pelo Banco Mundial, convencido principalmente pelos esforços de um americano, Al Mathews - que acabou sendo indicado posteriormente como presidente do painel do Dispute Review Board -, de que um DRB superaria os potenciais problemas previsíveis, seja em razão do grande porte do projeto, seja em virtude da nacionalidade das partes - uma empreiteira italiana e um engenheiro suíço, e a contratante Companhia de Eletricidade de Honduras, que nunca tinha executado projeto de grande porte, tampouco participado de contratos internacionais. ${ }^{23}$

Como resultado, a construção dos 260 metros de altura do El Cajón Dam Hydrolectric, conhecida como Central Hidroelétrica Francisco Morazán, foi finalizada dentro do prazo inicialmente previsto, sendo o DRB bem-sucedido.

Figura 1. El Cajon (Honduras) em pleno funcionamento

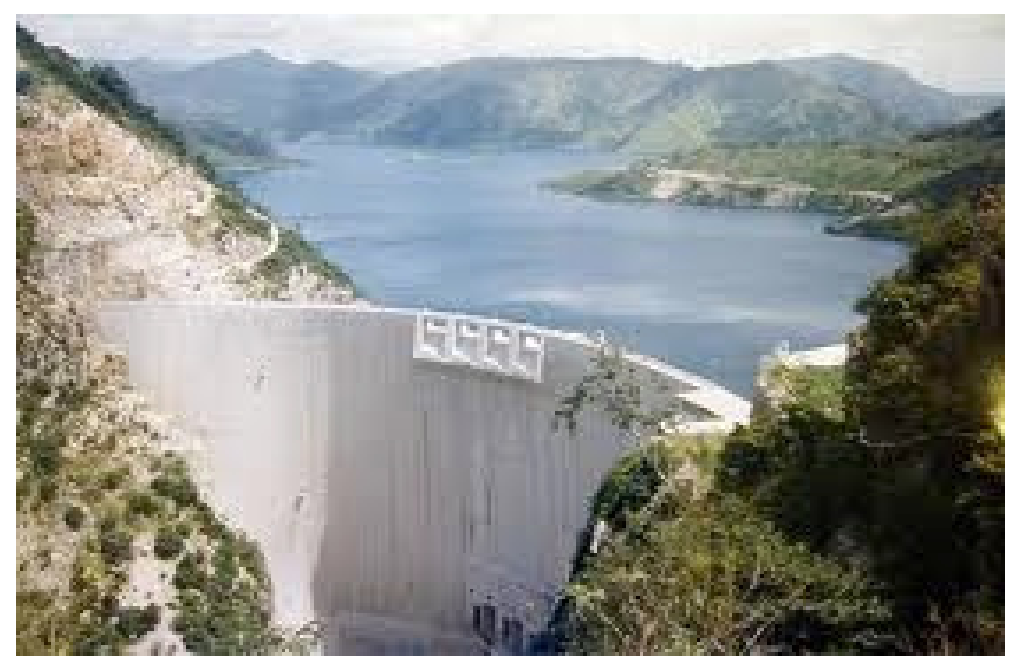

Fonte: Fotografia do Projeto Regional de Energia Elétrica do Centroamericano de Istmo, em 26,02.2006 (www.industcards.com).

\section{A CONSTRUÇÃO DO TERCEIRO JOGO DE ECLUSAS NO CANAL DO PANAMÁ}

Nos últimos anos, o Panamá tem se tornado importante foco de investimentos estrangeiros, alocando-se aproximadamente $U \$ 2,95$ bilhões para obras de infraestrutura no período de 2011

21 CYRIL, Chern. Chern on Dispute Board. Blackwell Publishing: Oxford, 2008, p. 08.

22 Омото, Toshihiko. Dispute Boards Resolution and Avoidance of Disputes in Construction

Contracts. In: The Japan Commercial Arbitration Association Newsletter. November 2009, n. 23.

23 CYRIL, Chern. Ob. cit., p.08. 
e 2012. Entre os relevantes projetos destacam-se a construção do primeiro metrô denominado "Projeto Linha 1 Metrô" e de um terminal adicional no Aeroporto Internacional Tocumen (Terminal Norte), além da reorganização do sistema de circulação de trânsito na cidade de Panamá, incluindo a construção de pistas e vias de acesso adicionais para veículos terrestres. ${ }^{24}$

Em 2010, o Panamá enquadrou-se, de acordo com o seu grau de investimentos, na classificação BBB, realizada pelas agências de avaliação Fitch Rating e Standard\&Poor's, ${ }^{25}$ que representa um indicador financeiro para potenciais investidores. Um mercado financeiramente ativo, somado às concessões milionárias, contudo, não é suficiente para atrair a atenção de investidores e bancos estrangeiros destinados a participar de contratos públicos. Isso porque sempre haverá o risco de não se chegar ao regular término do contrato, seja em decorrência de um ato de soberania estatal, seja porque há uma alegação de quebra contratual. Por outro lado, poderá ocorrer a necessidade de revisar as cláusulas contratuais ou de determinar a quantidade de pagamentos e indenizações decorrentes do término do contrato. Todas essas variáveis devem ser (e efetivamente são) consideradas pelos investidores estrangeiros antes de injetarem seu capital em determinado contrato público.

Acrescente-se, ainda, que o investidor estrangeiro não simpatiza com a sujeição de suas controvérsias ao Poder Judiciário, no qual os processos são longos e os juízes potencialmente tendenciosos em prol dos nacionais.

É a partir desse contexto que o Panamá tem compreendido a necessidade de o investidor estrangeiro resolver uma disputa sem ter que recorrer à fórmula tradicional de litígio judicial, adotando-se, assim, uma política favorável ao uso de mecanismos de resolução alternativa de controvérsias em contratos internacionais de infraestrutura pública de larga escala, entre os quais se destaca a expansão do Canal Panamá. Trata-se do projeto e da construção do terceiro jogo de eclusas, cuja obra foi estimada em $U \$ 5,25$ bilhões, a serem gastos entre 2007 a $2014 .{ }^{26}$

Figura 2. Canal do Panamá antes do início das obras, com os dois jogos de eclusas

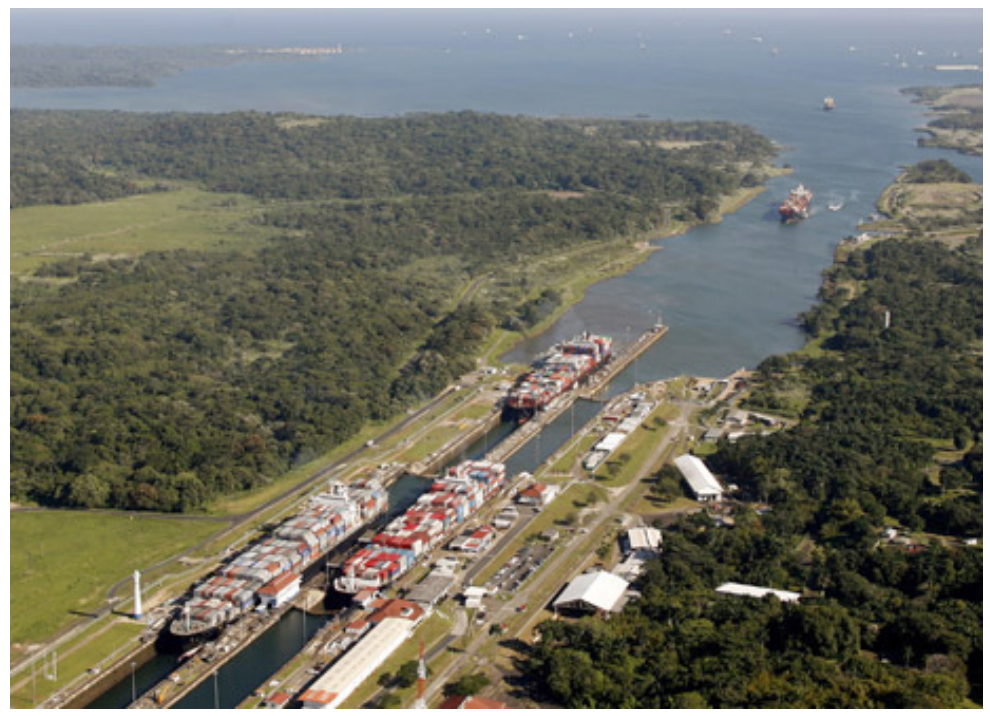

Fonte: Conexão Marítima (www.portosdeportugal.pt).

Nesse empreendimento, controvérsias entre empreiteiro e contratante (autoridade do Canal do Panamá) são resolvidas primeiramente por meio de Dispute Board, após se recorre à negociação e, finalmente, à arbitragem.

Uma vez instalada a controvérsia, esta se submete a um Dispute Adjudication Board (DAB), composto por três membros: dois nomeados por cada uma das partes e um terceiro, presidente,

24 ARIAS, Fernando; AUED, Fernando. Panama's ADR Push. In: The 2011 guide to litigation\&dispute resolution. International Financial Law Review. Disponível em: <www.arifa.com> em 15.09.2011, p.03.

25 Disponível em: < www.centralamericadata.biz> em 12.10.2011.

26 Disponível em <www.portalmaritimo.com> em 20.09.2011. 
designado pelos outros dois membros do DAB e aprovado pelas partes. A decisão deve ser proferida dentro de determinado prazo, após o recebimento pelo presidente de documentos referentes à controvérsia.

A decisão será vinculativa às partes, a menos que desejem revisar os termos por meio de um acordo amigável ou arbitragem. Se uma das partes não ficar satisfeita com a decisão proferida pelo $D A B$ ou se este não proferir sua decisão dentro do prazo assinalado, a parte interessada deverá comunicar a outra dentro de determinado prazo para o DAB proferir sua decisão ou, após receber o serviço da decisão para o DAB, prestar a devida assistência. Nessa última hipótese, a ausência de comunicação de insatisfação dentro do prazo assinalado torna a decisão do DAB final e vinculativa para as partes. ${ }^{27}$

Em princípio, a arbitragem só poderá ser iniciada se existir uma nota de insatisfação dada dentro dos prazos fixados e se as partes já tiverem tentado um acordo amigável após a divulgação de tal nota. Entretanto, se uma das partes deixar de cumprir a decisão do DAB e não tiver divulgado sua nota de insatisfação; a outra, prejudicada, poderá iniciar direto o procedimento arbitral para reivindicar o respectivo cumprimento. A arbitragem também poderá ser instalada direto por qualquer outra razão não mencionada pelo $D A B .^{28}$

Aos procedimentos da arbitragem constantes do contrato de construção aplicam-se as regras da ICC, além daquelas da International Bar Association sobre a obtenção de provas em arbitragem comercial internacional.

Exceto para disputas diretamente submetidas à arbitragem (determinar o cumprimento de uma decisão do $D A B$ ou no caso de ausência de apontamento de um DAB), os árbitros terão todos os poderes para rever a decisão do $D A B$ e não haverá nenhuma limitação para as evidências ou argumentos previamente submetidos à decisão do $D A B$, os quais serão considerados provas.

\section{PROJETO DE TWIN TUNNELS DA LINHA DE METRÔ SHEPPARD (CANADÁ)}

A linha de metrô Yonge Street da Cidade de Toronto, a primeira linha dessa natureza, foi inaugurada em 1954. No mês de janeiro daquele ano, a Comissão de Trânsito de Toronto (Toronto Transit Commission - TTC) tornou-se a única prestadora de serviços de transporte público na cidade, realizando as respectivas ampliações de linhas de metrô ao longo dos anos, que passaram a acompanhar o crescimento das populações suburbanas. ${ }^{29}$

Entre tais ampliações, destaca-se a linha de metrô Sheppard que levou oito anos e custou aproximadamente U\$1 bilhão, sendo inaugurada em novembro de 2001. Foi a primeira linha de metrô no Canadá separada por dois túneis (Twin Tunnels, em vernáculo Túneis Gêmeos) que foram construídos inteiramente por máquinas tuneladoras (tunnel boring machines - "TBMs"). ${ }^{30}$ São aproximadamente 2.7 milhas de extensão dos túneis gêmeos que correm lado a lado, separados por aproximadamente 40 pés e localizados de 15 a 85 pés abaixo da superfície leste da Avenida Sheppard.

27 ARIAS, Fernando; AUED, Fernando. Ob. cit., p.03.

28 Ibdem, p.04-05.

29 KIRSH, Harvey. Dispute Review Boards and Adjudication: Two Cutting-Edge ADR Processes in International construction. In: American Bar Association Annual Meeting "The Emerging Global Order in International Construction 'Disputology': The Top 10 Cutting-Edge ADR Processes Employed in Construction World Wide", 2008.

30 Vide MALLOT, Murray. Sheppard Subway Twin Tunnels Project. In: Rapid excavation and tunneling conference proceedings, 1999. 
Figura 3: Execução do Projeto Twin Tunnels da linha de metrô Sheppard de Toronto (Canadá)

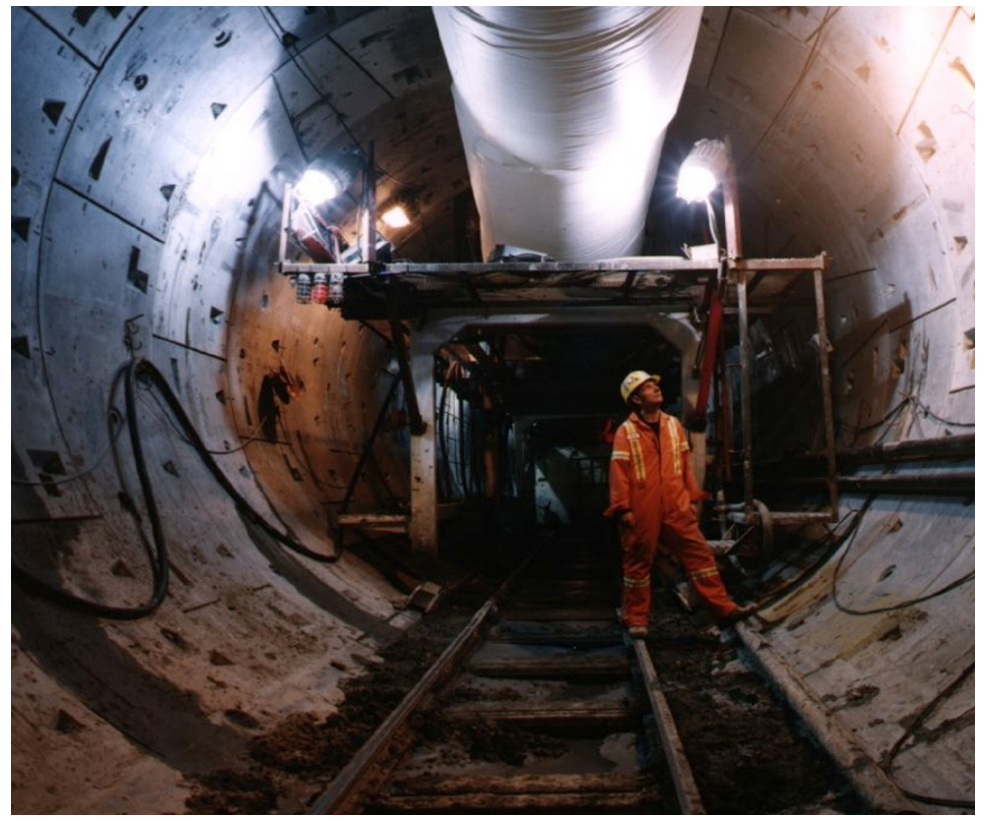

Fonte: www.mcnallycorp.com.

A TTC investiu em torno de 93 milhões de dólares canadenses no contrato de escavação do túnel com a joint venture MPF, composta pelas empresas McNally International Inc., PCL Constructors Eastern Inc. e Foundation Company Inc. (posteriormente conhecida como Aecon Construction Group Inc.). Do referido contrato constava previsão de Dispute Review Board (DRB), cujo propósito era prestar assistência na resolução de reivindicações e noutras disputas que surgissem no curso da execução do projeto Twin Tunnels, de maneira independente, justa e imparcial, a fim de evitar atrasos na construção e litígios. Nos poderes outorgados ao DRB, estava inclusa a previsão de recomendações escritas às partes, a fim de dar a respectiva assistência na resolução de tais controvérsias. Entretanto, embora não fossem vinculantes às partes, as recomendações do DRB tinham um grande peso para ambas as partes, TTC e MPF. ${ }^{31}$

De acordo com contrato Twin Tunnels, o DRB era composto da seguinte forma: um membro selecionado pela TTC e aprovado pela joint venture MPF; outro membro escolhido pela MPF e aprovado pela TTC; e um terceiro, selecionado pelos membros anteriormente escolhidos e aprovado pela MPF e TTC, que seria o presidente de todas as atividades do DRB. Previa o contrato, ainda, que os membros do DRB deveriam ter experiência com o tipo de construção relacionado ao Projeto Twin Tunnels e na interpretação dos documentos contratuais.

O membro DRB selecionado pela TTC e aprovado pela MPF era um engenheiro bem respeitado, que tinha sido Presidente de uma empresa de consultoria e possuía substancial experiência e competência em projeto de transporte coletivo e obras subterrâneas.

Já o membro DRB selecionado pela MPF e aprovado pela TTC era engenheiro de segurança, geotécnico e civil, e Professor de Engenharia Civil na Universidade Stanford, com experiência em perícias em casos que envolviam assuntos práticos de construção, contratos e geotecnia, e já tinha atuado tanto como Presidente quanto membro de inúmeros outros DRB.

O terceiro membro DRB, por sua vez, era um consultor de engenharia com substancial e larga experiência em gerenciamento de escavação de túnel, além de formação em contratos de construção subterrânea e considerável experiência em outros inúmeros DRB relativos à escavação de túnel, projetos de infraestrutura e construção de metrô.

Contudo, logo após o início da escavação do túnel, a MPF comunicou a TCC que estava incorrendo em custos adicionais decorrentes de problemas oriundos da elevada quantidade de espuma utilizada 31 KIRSH, Harvey. Ob. cit., p.09-10. 
para condicionamento do material escavado. Alegou que a quantidade do referido material que foi alocada para o fim de escavar com sucesso os túneis excedeu e muito a expectativa inicial. Como resultado disso, sustentou que os custos para descarte aumentaram significativamente. Além disso, argumentou que o transportador subcontratado foi obrigado a carregar o material do túnel escavado e condicionado a locais de descartes caros e inconvenientes, cujos custos excederam aqueles incluídos na sua oferta quando do início da contratação. ${ }^{32}$

Como consequência, a MPF submeteu um requerimento de 4.4 milhões de dólares canadenses de custos adicionais decorrentes da destinação do descarte do túnel, em face do qual a TTC sustentou que não existiam argumentos válidos para tal pretensão. Após instaladas as discussões preliminares, as partes concordaram em submeter a matéria perante o DRB para uma audiência formal.

Foi oportunizada a manifestação a ambas as partes que fizeram submissões escritas préaudiência, apresentaram provas fáticas e periciais e considerações finais pós-audiência.

Logo após, o DRB divulgou sua detalhada e abrangente recomendação escrita. Os três membros do Comitê, por unanimidade, rejeitaram o requerimento da MPF, declarando que esta não tinha respaldo para a compensação extra nos termos e condições do contrato.

Em razão dessa perspectiva restrita aos termos e às condições contratuais, a MPF notificou a TTC acerca de sua rejeição à recomendação do DRB (de acordo com o contrato), e iniciou os procedimentos para o litígio.

Os fatos, as questões, as reivindicações e as submissões que prosseguiram em litígio eram em tese idênticos àqueles que tinham sido submetidos perante o DRB. Entretanto, no seu requerimento, a MPF não fez qualquer referência à audiência anterior ou à recomendação do DRB. Em face disso, a TTC, em sua defesa, invocou que o requerimento apresentado pela MPF era precisamente 0 mesmo submetido anteriormente ao DRB há mais de dois anos e meio. A MPF, nesse caso, poderia ter suscitado, mas negligenciou o efeito não vinculativo e semelhante ao de mediação de todo o processo DRB, ou seja, que possuía caráter de composição. ${ }^{33}$

A TTC também sustentou que o início do referido litígio ensejaria o risco de o Tribunal proferir decisão diversa daquela dada há dois anos e meio pelo Comitê de três eminentemente qualificados e experientes profissionais do DRB. E essa inconsistência provocaria descrédito aos processos de resoluções alternativas de controvérsias e Dispute Board. ${ }^{34}$

Ademais, a TTC argumentou que, em sendo matéria de política pública, o início do litígio após a prévia rejeição, unânime e inequívoca, por DRB do mesmo requerimento, criaria um precedente que apenas serviria para desacreditar os benefícios da negociação, conceitos e processos de resolução de controvérsias e DRB, além de desestimular outras partes em outros projetos na tentativa de resolver suas disputas ao usar aqueles conceitos e processos em vez de litígio. ${ }^{35}$

A trajetória custosa e longa do litígio levou, então, aproximadamente dois anos e meio para se chegar à conclusão de que a rejeição unânime do requerimento da MPF por três experts seria um grande obstáculo a ser superado por ocasião do julgamento no Tribunal. ${ }^{36}$

Desse caso, é possível extrair três importantes lições: (i) não importa o quanto rigoroso seja, - Dispute Board deve respeitar os termos e as condições contratuais, não the cabendo reescrever ou reinterpretar o contrato para viabilizar uma solução aparentemente mais equitativa a uma determinada parte; (ii) embora a recomendação do DRB seja em geral não vinculativa e possa ser rejeitada por uma das partes, não se pode negar o seu respeitável peso para as partes, assim como a sua significativa influência para o resultado dos procedimentos legais subsequentes; (iii) apesar de oficialmente rejeitada por uma das partes, a recomendação do DRB constitui com frequência base para uma futura negociação entre as partes. ${ }^{37}$

32 KIRSH, Harvey. Ob. cit., p. 10.

33 MCENIRY, Geral. It's time for more DRBs in Canada. In: The Revay Report, vol. 29, number 2, june 2010.

34 KIRSH, Harvey. Ob. cit., p. 10.

35 KIRSH. Harvey. Ob. cit., p. 10.

36 MCENIRY, Geral. Ob. cit.

37 MCENIRY, Geral. Ob. cit. 


\section{CONSIDERAÇÕES FINAIS}

Os $\mathrm{DB}$, como qualquer outro mecanismo alternativo de resolução de controvérsias, têm por finalidade precípua evitar litígio, assim como o recurso a procedimentos adversariais, tais como arbitragem e Judiciário.

Afastar-se dos mecanismos usais de solução de controvérsias, especialmente quando considerado o Poder Judiciário e a cultura dominante no país, requer um especial esforço e uma mudança paradigmática, substituindo-se a figura da autoridade (imposta ou escolhida) pela atitude cooperativa, ainda que esta cooperação não derive necessariamente de um fundamento teórico ou moral, mas da percepção do impacto em termos de custos de transação, chegar-se ao estágio do litígio.

Contudo se pode inferir que na prática isso nem sempre é possível, o que pode transformar o DB em uma etapa adicional antes de se chegar à efetiva solução da disputa. Vale dizer que, em vez de simplificar, o DB acaba por tornar a resolução do conflito mais morosa e custosa, ante as despesas decorrentes de sua instalação (p.ex., profissionais, visitas ao empreendimento, relatórios, etc.).

Apesar disso, não se pode negligenciar que as recomendações do DB, mesmo quando não vinculativas ou desprovidas de enforcement se vinculativas, constituem poderoso instrumento de persuasão apto a influenciar as decisões arbitrais ou do próprio Judiciário. E, nesse contexto, indubitável que o DB constitui um desestímulo à parte vencida que refletirá mais antes de ingressar judicialmente ou iniciar um procedimento arbitral.

Ainda que se cogitem custos elevados para a instalação do DB, constata-se também que tal mecanismo tem sido frequente em empreendimentos de grande porte, nos quais as despesas são compensáveis ao longo da execução da obra. E a designação prematura dos membros do DB sem dúvidas torna o mecanismo um poderoso aliado das partes para o sucesso do empreendimento.

Outro ponto que merece atenção diz respeito à natureza vinculante das decisões do DB que acaba por assemelhar o mecanismo à arbitragem, muito embora aquele careça de enforcement. Em razão da composição eminentemente técnica, o DB profere decisões mais aceitáveis pelas partes se comparadas às judiciais ou, até mesmo, às arbitrais. Além disso, a instalação do DB no início do empreendimento viabiliza um contato maior dos profissionais que compõem o $\mathrm{DB}$, criando laços mais acentuados com as partes do que qualquer outro mecanismo alternativo de solução de controvérsias.

É por essas razões que, a despeito de suas desvantagens, sob o ponto de vista da eficiência econômica, o Dispute Board tem sido o mecanismo mais indicado e utilizado em grandes empreendimentos do mundo todo por prestigiar, sobretudo, a multidisciplinaridade e a cooperação entre os agentes econômicos na construção de determinada relação para o futuro.

\section{REFERÊNCIAS}

ARAÚJO, Fernando. Teoria Econômica do Contrato. Lisboa: Almedina, 2007.

ARIAS, Fernando; AUED, Fernando. Panama's ADR Push. In: The 2011 guide to litigation\&dispute resolution. International Financial Law Review. Disponível em: <www.arifa.com> em 15.09.2011.

AXELROD, Robert. The evolution of cooperation. New York: Basic Books, Inc.,Publishers, 1984.

CYRIL, Chern. Chern on Dispute Board. Blackwell Publishing: Oxford, 2008.

EDGERTON, William. DRBF survey results: at look the evolution the Dispute Board process. In: Dispute Board Resolution Foundation, Forum, vol.15, maio 2011. Disponível em: <http://www.sergepisapia.ca> em 10.09.2011.

KIRSH. Harvey. Dispute Review Boards and Adjudication: Two Cutting-Edge ADR Processes in International construction. In: American Bar Association Annual Meeting "The Emerging Global Order in International Construction 'Disputology': The Top 10 Cutting-Edge ADR Processes Employed in Construction World Wide", 2008.

KOROBKIN, Russell; DOHERTY, Joseph. Who Wins in Settlement Negotiations. American Law and Economics Review, Vol. 11, n. 1, 2009, pp. 162-208. 
MALLOT, Murray. Sheppard Subway Twin Tunnels Project. In: Rapid excavation and tunneling conference proceedings, 1999.

MCENIRY, Geral. It's time for more DRBs in Canada. In: The Revay Report, vol. 29, number 2, june 2010.

ОМото, Toshihiko. Dispute Boards Resolution and Avoidance of Disputes in Construction Contracts. In: The Japan Commercial Arbitration Association Newsletter. November 2009, n. 23.

OWEN, Gwyn; TOTTERDILL, Brian. Dispute Boards: procedures and practice. Thomas Telford Publishing: London, 2008.

RIBEIRO, Marcia C. P.; GALESKI JR, Irineu. Teoria Geral dos Contratos: contratos empresariais e análise econômica. Rio de Janeiro: Elsevier, 2009.

ROSA, Pérsio Thomaz Ferreira. Os dispute boards e o contrato de construção. Disponível em: < www.frosa.com.br> em 10.09.2011.

TALPIS, Jeffrey A. Prevenção de disputas decorrentes de contratos internacionais. Tradução de Giovani Ribeiro Rodrigues Alves e Caroline Sampaio de Almeida. Revisão de Marcia Carla Pereira Ribeiro. In: MEIRELLES, Jussara Maria Leal de; RIBEIRO, Marcia Carla Pereira (Coord.). Direito e Desenvolvimento: Biomedicina, Tecnologia e Sociedade Globalizada, Belo Horizonte: Editora Fórum, 2011. 